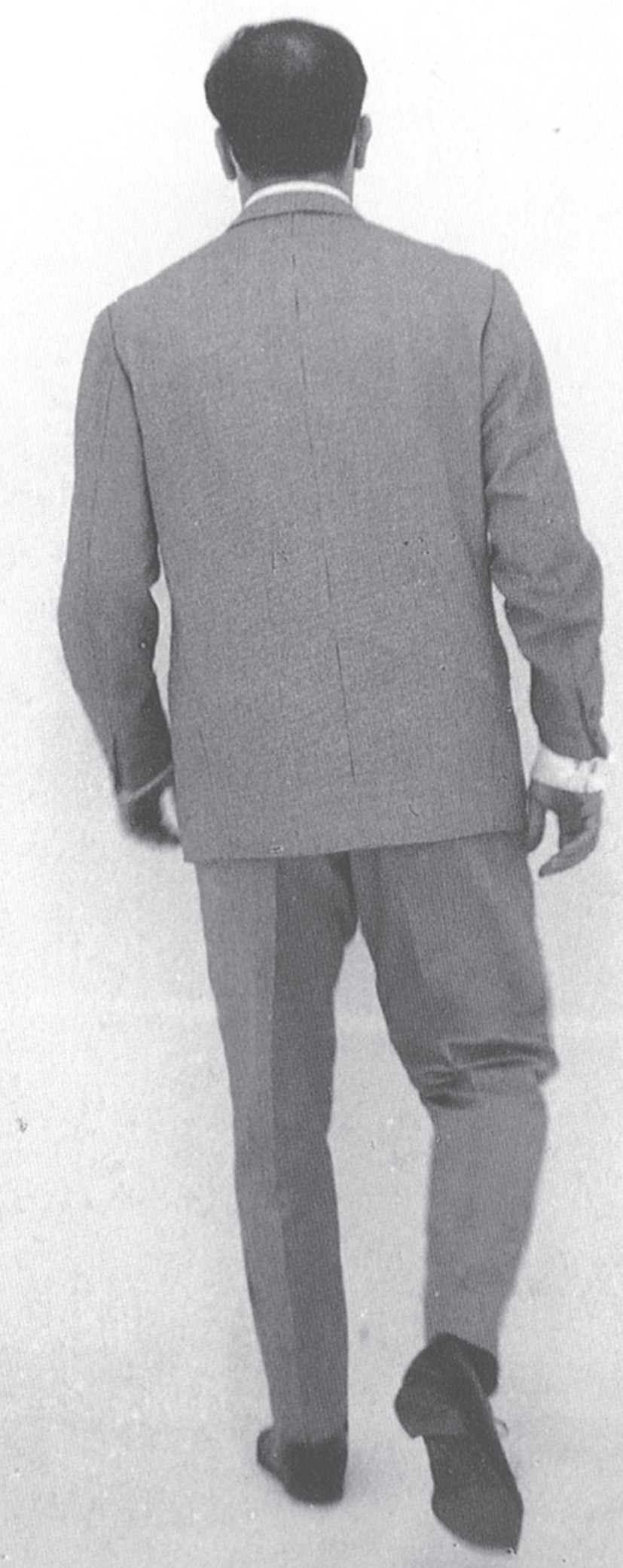




\section{Yve-Alain Bois}

\section{A relevância de Klein hoje*}

palavras-chave: Yves Klein; Theodor

Adorno; Richard

Wagner; indústria cultural; espetáculo

keywords: Yves Klein; Theodor Adorno; Richard Wagner; culture industry; spectacle
Para se aproximar do trabalho de Yves Klein, o autor reproduz alguns argumentos de Theodor Adorno sobre a música de Wagner, formulados em dois momentos - em 1937-1938, sob a experiência do fascismo, e em 1963, com 30 anos de "distância". No primeiro texto, Adorno mostrava, na obra de Wagner, os aspectos que traíam a gestação do fascismo. No segundo reconhecia que, com o novo momento histórico, outras camadas vinham à baila naquela obra; ela havia mudado, e a posição de Adorno em relação a ela tornava-se "ambivalente". Partindo do paralelismo com Wagner, Bois revisita o trabalho de Klein buscando revelar, em seus ardis e encenações, para além da simples adesão aos expedientes da indústria cultural, uma espetacularização do próprio espetáculo, que acaba por esvaziá-lo.

In order to approach the work of Yves Klein, the author recalls the arguments of Theodor Adorno in regard to the music of Richard Wagner, presented in two different texts - the first written in 1937-1938, under the experience of fascism, and the other in 1963, with a "distance" of 30 years. In the first text, Adorno highlighted, in the work of Wagner, the aspects that betrayed the birth of fascism. In the second one he recognized that, along with the new historical moment, other layers emerged in Wagner's work; it had changed, and Adorno's position toward it became "ambivalent". Starting with a parallelism with Wagner, Bois reexamines the work of Yves Klein, trying to reveal, in his use of staging and artifice, beyond the mere acceptance of the expedients of the culture industry, a spectacularization of spectacle itself, that ends up by deflating it. 
* Este texto foi originalmente publicado em October,

Cambridge, Mass.:

MIT Press, n. 119, p. 75-93, inverno 2007.

1. 0 Instituto de Pesquisa Social [Institut für Sozialforschung] foi fundado em Frankfurtsobre-o-Main, Alemanha, em 1923, e tornou-se conhecido como berço institucional da Escola de Frankfurt e da teoria crítica. Em 1930, Max Horkheimer passou a dirigir a instituição, da qual seria forte referência intelectual, editando a revista Zeitschrift für

sozialforschung [Revista de pesquisa social]. Na década de 1930, a crescente influência dos nazistas levou os fundadores a decidir

preparar a transferência do Instituto para fora

da Alemanha. Em 1933, após a ascensão de

Hitler, ele se transferiu para Genebra e no ano seguinte, 1934, para Nova lorque. Em Nova lorque afiliou-se à Universidade de Columbia, e sua revista Zeitschrift für sozialforschung passou a chamar-se Studies in philosophy and social science [Estudos em filosofia e ciência social].

Foi nesse contexto que muitos importantes

trabalhos dos pensadores da Escola de Frankfurt começaram a ganhar espaço, sendo recebidos favoravelmente nas universidades inglesas e norte-americanas.

0 Instituto reabriu em Frankfurt em 1951. [Nota da revisora da tradução].
Em uma palestra realizada em Berlim, em setembro de 1963, Theodor W. Adorno revisitou seu In search of Wagner [Em busca de Wagner] publicado cerca de 10 anos antes. Escrito quando morava em Londres, entre o outono de 1937 e a primavera de 1938, esse livro pequeno e incisivo foi marcado pela experiência do fascismo. Adorno não estava preocupado com o uso da música de Wagner na propaganda nazista, mas, alinhado com o trabalho que completava, na época, com seus colegas do Institut für Sozialforschung ${ }^{1}$, ele pretendia mostrar como essa música, que surgiu das ruínas de uma cultura burguesa em plena crise, elucidava a lenta gestação do fascismo, revelando sua genealogia muda de um modo exemplar² . Embora Adorno negue, seu texto de 1963 é uma forma de autocrítica ou, no mínimo, uma declaração reveladora. Ele observa, em relação ao trabalho de Wagner, que não se pode, por certo não naquela época, "ignorar seu aspecto político", mas que a situação na qual esse trabalho fora recebido havia mudado. Por um lado, "ganhamos distância nos últimos trinta anos. Wagner não representa mais, como em minha juventude, o mundo dos pais, mas o dos avós [...]. Ganhamos muita liberdade para com Wagner enquanto objeto de interesse: nosso laço afetivo com ele se afrouxou" ${ }^{\text {" }}$. Por outro lado, acontece que "o antiwagnerismo estético entrou na onda do chamado movimento neoclássico, [que não é] absolutamente progressista do ponto de vista político"4 (é bastante conhecida a tendência de Adorno a favor de Schoenberg e da Escola Vienense - e contra Stravinsky).

$\mathrm{O}$ ponto mais destacado do argumento de Adorno encontra-se nas linhas que se seguem:

Contudo, o que mudou a respeito de Wagner [...] não é meramente o impacto nos outros, mas seu próprio trabalho, o trabalho em si mesmo. Aí está a base da relevância de Wagner; não algum segundo triunfo póstumo ou a esperada derrota do neobarroco. Como entidades espirituais, obras de arte não são completas em si mesmas. Elas criam um campo magnético de todas as possíveis intenções e forças, de tendências internas e outras, opostas a estas, de elementos bemsucedidos e necessariamente malsucedidos. Objetivamente, novas camadas se desprendem de modo contínuo, vêm à baila; outras se tornam irrelevantes e desaparecem. Relacionamo-nos com uma obra de arte não, como se diz amiúde, meramente adaptando-a a fim de ajustá-la a uma nova situação, mas decifrando, no interior dela, coisas com as quais temos uma reação historicamente diferente. A posição de consciência que experimento como propriamente minha em face de Wagner todas as vezes em que me deparo com ele, posição que não é só minha, é ainda mais merecedora do epíteto de "ambivalente" do que a posição anterior - uma oscilação entre atração e repulsa. ${ }^{5}$

O que se segue é uma definição de ambivalência: uma "relação acenada a algo que não se dominou; comportamo-nos de modo ambivalente em face de algo que ainda não compreendemos”. Adorno complementa: 
2. ADORNO, Theodor W. In search of Wagner. Trad. Rodney Livingstone. Londres: Verso, 2005.

Quatro capítulos do livro foram publicados em

1932, mas o volume, intitulado Versuch über Wagner, só foi publicado em 1952.

3. Idem, Wagner's relevance for today. In: LEPPERT, Richard

(Ed.). Essays on music. Berkeley: University of California Press, 2002, p. 584-585.

4. Ibidem, p. 586. Mais adiante, Adorno caracteriza o movimento antiwagneriano como “a primeira incidência em larga escala do ressentimento contra a arte moderna na Alemanha" (p. 587)

5. Ibidem, p. 586-587.

6. Ibidem, p. 587-588. Em 1963, segundo Adorno, Wagner era mais conhecido por certas peças na esteira de $A$ valquíria (1856) do que pela arquitetura complexa de Siegfried (1871).

Sua obra, em resumo, foi reduzida a alguns clichês: "As obras de

Wagner que não lograram ganhar a apreciação do público são precisamente as mais modernas, aquelas com a técnica mais corajosamente progressista e, portanto, as mais afastadas das convenções." (p. 588).

7. RESTANY, Pierre. Vignt ans après. In: Yves Klein. Catálogo de exposição. Paris: Musée National d'Art Moderne, Centre Pompidou, 1983,

p. 70.0 texto segue com um ataque de má-fé
"Em resposta a isso, a primeira tarefa à vista seria simplesmente experimentar o trabalho wagneriano plenamente - algo que até hoje, apesar de todo o sucesso externo, não foi alcançado" ${ }^{\text {. }}$

Eu diria que ao defrontarmos Yves Klein hoje, estamos na mesma situação de Adorno quando defrontava Wagner há mais de quarenta anos. Evidentemente, o paralelo é reforçado pelo fato de que as duas obras têm muito em comum, como veremos. Mas o que é importante de se notar aqui é que o Klein de hoje não é o mesmo dos anos 1960. Isso decerto não significa - ao contrário do que Pierre Restany queria acreditar já há mais de vinte anos - que esse novo Klein, não mais do que o novo Wagner de Adorno, possa ser expurgado de todas as suspeitas envolvendo seu eu antigo ou a identidade que ele forjou para si mesmo (além disso, frequentemente usando Restany como um porta-voz).

Restany em 1982:

Quando penso que em 1969, na época da primeira retrospectiva de Yves Klein em um museu de Paris, Christiane Duparc ainda podia escrever: "O irritante a respeito de Yves Klein é o molho simbólico, o resíduo ao modo de Cristo, Santa Rita, os Rosacrucianos [...], Nostradamus, judô místico, a Ordem de São Sebastião [...]. Ele chafurdou em um tipo de religiosidade exasperante", e quando eu comparo a mentalidade da mídia parisiense em 1982 a isso, mal posso acreditar no que vejo. ${ }^{7}$

Leal ao seu papel de defensor oficial, Restany parecia acreditar que as artimanhas espiritualistas de Klein não eram mais problema na época da retrospectiva do artista em 1983 no Musée National d'Art Moderne (em cujo catálogo essas frases foram publicadas). Bem ao contrário, um dos principais fatores de mudança que haviam ocorrido no legado de Klein era a análise crítica do "tempero" do artista - especialmente o estudo meticuloso do rosacrucianismo de Klein conduzido por Thomas McEvilley, justamente no catálogo dessa mesma exposição, para o grande desprazer de Restany! (McEvilley discute os numerosos empréstimos que Klein fez da filosofia rosacruciana antes de o artista perceber que apelar para a autoridade de Gaston Bachelard era mais respeitável do que invocar Max Heinel $^{8}$ ). Para ser ainda mais severo com Restany - mas ele merece, ainda que postumamente, tal severidade, pelo desprezo que mostrou por seus sucessores -, sabemos hoje muito mais sobre Klein, agora que o monopólio quase exclusivo que esse crítico de arte teve sobre a obra do artista acabou. Não fossem os estudos de arquivo conduzidos por McEvilley (sobre o rosacrucianismo, mas também sobre a biografia e a patologia de Klein, em um ensaio mais longo e mais ambicioso, igualmente publicado no catálogo de $1983^{9}$ ); Nan Rosenthal (veja o estudo fundamental, no mesmo catálogo, sobre aquilo que eu chamaria de fraudes ostensivas de Klein - o 
a McEvilley como um dos representantes da "disposição de espírito melindrada e meticulosa" da crítica de arte e da história da arte norteamericanas, contra a qual Restany opõe, demagogicamente, os depoimentos generosos oferecidos por artistas. 0 catálogo será citado, daqui em diante, como MNAM.

8. Os ensaios de Thomas McEvilley e de Nan Rosenthal foram publicados originalmente no catálogo das instituições norteamericanas que sediaram a retrospectiva de Klein la Rice University, em Houston, o Museu de Arte Contemporânea, em Chicago, e o Solomon R.

Guggenheim Museum, em Nova lorque), catálogo este anterior ao do Centre

Pompidou. Cf. Yves Klein e o Rosacrucianismo. In: Yves Klein. Catálogo de exposição. Houston: Institute for the Arts, Rice University, p. 238-254, 1982. Esse catálogo será citado, daqui em diante, como Houston.

9. MCEVILLEY, Thomas. Yves Klein, conquistador of the void. In: Houston, op. cit., p. 19-87.

10. ROSENTHAL, Nan. Assisted levitation: the art of Yves Klein. In: Houston, op. cit., p. 89-136.

11. STICH, Sidra. Yves Klein. Stuttgart:

Cantz, 1994. Essa monografia funcionou como um catálogo da retrospectiva itinerante de Klein, organizada por Stich, no Museum

Ludwig (Colônia), no Kunstsammlung Nordrhein-Westfalen presente ensaio baseia-se fortemente nesse texto ${ }^{10}$ ); Sidra Stich (que em sua monografia-catálogo sustenta a hipótese de seus dois predecessores com documentação massiva ${ }^{11}$ ), e, por último, Denys Riout (que em seu notável e bem recente Yves Klein: manifester l'immatériel finalmente nos oferece uma descrição minuciosa do aparato parergonico $^{12}$ que Klein invocou para suas intervenções e exibições públicas, transformando cada uma delas em um tipo de Gesamtkunstwerk grandioso ${ }^{13}$ ) -, não fossem os trabalhos persistentes desses quatro mosqueteiros da pesquisa (devemos também incluir a edição excelente dos escritos de Klein por Marie-Anne Sichère e Didier Semin ${ }^{14}$ ), nós ainda hoje estaríamos chafurdando no mesmo molho, para adotar uma vez mais a metáfora peremptória de Christiane Duparc.

Voltemos a Wagner ou aos Wagner de Adorno. Para o teórico (que, não devemos esquecer, foi também um pianista e compositor, na tradição de seu professor, Alban Berg), Wagner é o artista que marcou o início do reinado daquilo que o filósofo chamou de indústria cultural: na música de Wagner, o modernismo promissor é o que se preserva contra tal veneno como um anticorpo, mas o que propicia o advento dele é a demagogia e o autoritarismo. Wagner representa uma guinada histórica: o momento em que, ao se tornar puro espetáculo, a arte não é, doravante, senão mercadoria, e o espectador, um consumidor passivo a quem se deve seduzir e absorver.

Ao lermos o livro de Adorno, acabamos nos perguntando o que ele, de fato, poderia ter dito de diferente sobre Klein: por exemplo, quando fala do "caráter social" de Wagner (o rebelde que se tornou um mendigo, a criança mimada que se identifica com a ordem estabelecida contra a qual, todavia, está persuadida a lutar); de seu diletantismo (que, de acordo com Thomas Mann, é a marca da sua falta de educação formal e a base da ideia mesma de uma "síntese das artes"); da necessidade poética que Wagner tem da hipérbole; de como o trabalho é eclipsado em suas produções teatrais (essencial para o que Adorno chama de aspecto fantasmagórico do teatro em suas óperas, a meta de tal eclipse sendo criar "a ilusão da realidade absoluta do irreal"15); da fascinação com as possibilidades materiais da tecnologia e com os truques habilidosos envolvendo façanhas teatrais em mágica; da frequentemente sádica manipulação de seu público ${ }^{16}$, a qual se associa à sua obediência a ele (o sintoma mais pungente dela sendo, talvez, a busca pelo sucesso a qualquer preço); de seu ideal ascético (a autoimolação necessária para qualquer martirológio); da constante referência ao mito (mito de um retorno a um passado pré-histórico paradoxalmente visto como um presente eterno e, assim, como uma revogação do futuro ${ }^{17}$ ); do sonho, por fim, com uma época congelada que, no entanto, jamais encontra repouso.

A acusação de Adorno, que gradual e imperceptivelmente transferi para Klein, não apenas me ajudou a entender o cerne de minha própria 
(Dusseldorf), na Hayward Gallery (Londres) e no Museo Nacional Centro de Arte Reina Sofia

(Madri).

12. 0 neologismo deriva do grego ergon, trabalho; "par + ergon" significando, portanto, algo que se define como acessório em relação a um trabalho ou elemento principal. 0 termo é usado pelo filósofo Jacques Derrida para designar algo que se apresenta para além do trabalho (ergon), externo

a ele, sendo, contudo, irrecorrivelmente parte dele. [Nota da revisora da tradução]

13. RIOUT, Denys. Yves Klein: manifester l'immatériel. Paris: Gallimard, 2004.

14. KLEIN, Yves. Le dépassement de la problématique de l'art et autres écrits. Ed. Maria-Anne Sichère; Didier Semin. Paris: École Nationale Supérieure des Beaux-Arts, 2003. Este livro será citado, de agora em diante, como DEP.

15. Adorno, citando o musicólogo Paul Bekker, em In search of Wagner, op. cit., p. 79. Esse aspecto "fantasmagórico" da produção de Klein não é em lugar algum mais impactante que em seus projetos arquiteturais, em especial toda a série de desenhos "urbanísticos" feitos para ele por Claude Parent, em que o enorme maquinário que ele visionava para sua "arquitetura de ar" e suas fontes de fogo está escondido no subsolo. resistência a certos aspectos do seu trabalho, sobretudo a seu exibicionismo [showcasing] (incluindo Restany), como também a resistência muito mais forte do meu caríssimo amigo e adorniano estrito, Benjamin Buchloh. Para ele, com efeito, Klein é o artista, por excelência, do capitalismo avançado; ele completa a apoteose da indústria cultural de que Wagner foi tão somente o início profético. Em uma Europa devastada pela guerra, Klein demonstrou, mais do que qualquer outro, que "a tentativa de redimir a espiritualidade por meios artísticos no momento da ascensão do controle universal da cultura de massa revestiria inevitavelmente o espiritual de uma sórdida (involuntária) paródia”. Buchloh prossegue: "Ao fazer sua obra dependente, de um modo manifesto, de todos os dispositifs previamente escondidos (por exemplo, os espaços da publicidade e os expedientes da promoção), Klein "se tornaria o [...] artista europeu do pós-guerra a iniciar não apenas uma estética da contingência discursiva e institucional total, mas também da espetacularização total”18.

No entanto, se o livro que Adorno escreveu no exílio levou-me ao limiar de minhas reservas em relação à obra de Klein (ergon) e à sua embalagem elaborada (parerga), foi a conferência de 1963 que me deu uma chave, permitindo-me atravessar a barreira e ultrapassar aquele limiar. Há várias razões para isso, mas vou discutir aqui apenas as duas mais importantes. A primeira consiste na seguinte observação a respeito do que há de fraudulento em Wagner: Adorno nota que, na obra de Wagner, "o que é magnífico [...] não pode ser claramente separado do que é questionável. Um dificilmente pode ser alcançado sem o outro; seu conteúdo de verdade e aqueles elementos que a crítica legítima julgou questionáveis são mutuamente interdependentes [...]; não há como escapar a esse entrelaçamento do verdadeiro e do falso em sua obra" ${ }^{19}$. A segunda, que é, em essência, parcialmente relacionada à primeira, surge da análise que Adorno oferece do papel do mito na obra de Wagner (ele fala, mais especificamente, sobre mitos violentos, mas isso se aplica também ao restante, de modo notável a todas as referências à "natureza"). Por esse papel nunca ser ocultado, por se revelar em estado, "a obra, não obstante sua tendência mitificadora, é uma denúncia do mito, quer queira ou não"20.

Desde o início, Yves Klein toca no tema do fraudulento - no que pode ser chamado seu ato de batismo. Nan Rosenthal foi a primeira a chamar a atenção para os pequenos "livros" que Klein "publicou” em Madri antes de optar definitivamente por uma carreira artística, Yves peintures e sua contraparte irônica, Haguernault peintures ("livro" é claramente um exagero, do qual Klein frequentemente lançou mão mais tarde, ao se referir a esses folhetos de cerca de quinze pequenas páginas; "publicação" é ainda mais incorreto: longe das 150 cópias numeradas anunciadas no cólofon, havia somente algumas e é muito provável que grande parte delas tenha sido produzida apenas postumamente, a partir dos materiais que Klein havia trazido da Espanha). 
16. O lado sádico de

Klein alcança o ápice em seus projetos teatrais; veja-se, por exemplo, o intitulado

Pure sensibility e publicado no Dimanche,

“o jornal de um dia

só”, para o qual ele

imaginou amordaçar e acorrentar cada

espectador ao seu

assento até o final da apresentação. Cf. DEP, op. cit., p. 182.

17. 0 Éden antes da Queda londe todos vivem nus) é o lugar utópico ao qual Klein se refere constantemente em seus escritos.

18. BUCHLOH, Benjamin H. D. Plenty or nothing: from Yves Klein's Le vide to Arman's Le plein. In: Neo-Avantgarde and culture industry: essays on European and American art from 1955 to 1975. Cambridge, Mass.: MIT Press, 2000,

p. 269. Ver também, do mesmo autor: The primary colors for the second time. October, n. 38, p. 41-52, verão 1986; Klein and poses. Artforum, 33, n. 10, p. 93-97; 130; 136, verão

1995.

19. ADORNO, op. cit., 2002, p. 596.

20. Ibidem, p. 589.

21. Ver o Poème optique de Man Ray, publicado em 391 lo periódico editado por Francis Picabia), $\mathrm{n}$.

17, p. 3, jun. 1924. É perfeitamente possível que Klein tenha se familiarizado com o poema de Man Ray
Yves peintures é um caderno de reproduções coloridas enfeitado com um prefácio, em sintonia com o bem estabelecido modelo do catálogo de exposição em galeria comercial chique (ilustrações coloridas, papéis encorpados, um prefácio: tudo conota luxo). O primeiro elemento surpresa encontra-se no "prefácio": entre seu título genérico ("Prefácio") e o nome do "autor" (Claude Pascal, amigo de infância de Klein e poeta que concordou em emprestar seu nome para esse ritual de deleção simbólico), o "texto" consiste apenas de listras horizontais imitando o layout tipográfico de um ensaio (linhas impressas, parágrafos), muito similar ao Poème optique publicado por Man Ray em 1924, que imita em código Morse a configuração de um soneto ${ }^{21}$. A segunda surpresa (na época, importante), é que as "reproduções" em cores são, claro, retângulos monocromáticos (o fato de esses pedaços de papel colorido serem colados à mão nas páginas brancas não era necessariamente uma extravagância; pelo contrário, imitar a prática da Skira, então considerada o mais alto padrão em publicação de livros de arte, acentuou a conotação de luxo). O terceiro aspecto incomum diz respeito às "legendas" abaixo dos recortes de papel [paper cutouts] (com o último termo refiro-me deliberadamente a Matisse, que devia estar no radar de Klein $)^{22}$. Essas legendas saem todas do mesmo molde: à esquerda, o nome Yves; à direita, o nome de um lugar, seguido de uma data e de uma dimensão da "obra" entre parênteses. Por exemplo, "Yves/em Londres, 1950 (195 x 97)" ou "Yves/em Tóquio, 1953 (11 x 65)".

Como Rosenthal demonstrou de modo claro, as "obras" supostamente reproduzidas em Yves peintures não existiam ainda, e de fato nunca chegariam a existir, a menos que nós - tal é, provavelmente, a interpretação com a qual Klein teria assentido, caso alguém o tivesse pressionado a esse respeito tivéssemos de considerar sua simples concepção uma condição necessária e suficiente para sua existência (a variação da data, de 1950 a 1954, pretendia, essencialmente, afirmar que o "artista" havia tido a ideia de pinturas monocromáticas já em 1950, muito antes que pudesse considerar-se a si mesmo um artista, o que, de fato, muitos documentos e relatos confirmam). Mas como Rosenthal também nota, e embora Klein se referisse a esse trabalho como uma "seleção de reproduções de sua obra" (removendo as aspas que ele originalmente havia usado em "reprodução de" no rascunho de uma carta que descrevia o pequeno volume $)^{23}$, vários indícios nos levam, provocativamente, a suspeitar de algum truque: as frases mudas assinadas por Claude Pascal debocham, sem dúvida, da tradição das belles lettres que era popular no mundo da arte em Paris (e agora em Nova Iorque; o prefácio do catálogo da exposição é um exercício necessário para qualquer homem de letras que se preze, assim como o é esse suporte para qualquer artista emergente); a natureza monocromática das "obras" que se alegam reproduzidas é um 
através de François

Dufrêne, um amigo

de muitos anos, que

era, então, um poeta

letrista. Sobre Klein e o

movimento letrista, ver

STICH, op. cit., p. 31-34; 48-49.

22. Sobre Klein e Matisse, ver ROSENTHAL, op. cit, p. 132, nota 51. Em particular, ficamos sabendo ali que, em dezembro de 1953, a mãe de Klein, Marie

Raymond, publicou um artigo sobre Matisse em que "os recortes são extensamente discutidos e são reproduzidos".

23. Cf. ibidem, p. 98. Como nota Rosenthal, na versão final de uma carta enviada a Jacques Tournier em

5 de agosto de 1955 ,

Klein procurou dar substância ao mito de que ele era um jovem pintor com um corpo de trabalhos, colecionadores e projetos em que colaborava com arquitetos. Yves

peintures, ele escreve, está "esgotado no momento, mas a editora tem, creio eu, algumas poucas cópias avulsas". Carta publicada em DEP, op. cit., p. 329.

24. A interpretação mais lógica dessas indicações geográficas

Imas a menos convencional para um catálogo de exposição) seria a de que se referem ao lugar onde as "obras reproduzidas"

foram feitas. Essa interpretação é reforçada pelo fato de ataque frontal e um embuste irônico sobre o páthos burlesco da art informel que então dominava a cena (retornarei a este ponto); a repetição absurda da palavra "Yves" em cada legenda (um primeiro nome, por isso um termo genérico, aqui balbuciado como um leitmotiv, como que em uma repetição infindável - um processo wagneriano, se é que há um - era o único método de afirmar qualquer identidade); as anotações geográficas estranhas (em Paris, em Londres, em Madri, em Tóquio, em Nice: em todas as cidades onde Klein viveu e "trabalhou" ${ }^{24}$, e, finalmente, as dimensões.

Conforme escreve Rosenthal, "as dimensões de altura e largura em cada legenda são medidas que, no caso de pinturas, e na ausência da abreviação 'cm' ou da palavra 'centímetros', declaram significar centímetros; acontece que as dimensões de Klein não descrevem o que é presumivelmente miniaturizado pela reprodução, mas justo o que está lá, a altura e a largura em milímetros dos papéis coloridos”25. Essa correspondência exata entre as dimensões reais dos retângulos de papel colorido e as dimensões simbólicas (sem indicação de escala) das pinturas virtuais é essencial ao jogo de espelhos em que Klein nos submerge essencial tanto para o "entrelaçamento do verdadeiro e do falso" quanto para a "denúncia do mito" de que Adorno fala com relação a Wagner.

Talvez devêssemos enfatizar o fato de que o início de Klein foi pleno de fúria. Ele desprezava seus pais, ambos artistas (o pai, figurativo, e a mãe, bem conhecida entre o grupo dos abstratos), por terem-no negligenciado em favor de suas carreiras (frequentemente vivia com sua adorável Tia Rose, que arcou com seus caprichos até o fim); esteve presente no meio de vanguarda boêmio a que sua mãe pertencia e ficou rapidamente enjoado dos discursos de salão que ela fazia em suas "segundas-feiras". Foi com o cinismo blasé de um adolescente, como um refinado etnologista, que ele observou as engrenagens do mundo da arte, a pompa dos críticos, a economia promocional; ele também aprendeu história da arte como por osmose. Acima de tudo, a "arte abstrata" rapidamente o repugnou, com as tendências geométricas póscubistas a que sua mãe aderiu (ela expôs na galeria Denise René), e também com a art informel (precocemente, e de modo perspicaz, ele associou ambas as tendências). Georges Mathieu atraiu sua atenção desde muito cedo: este se tornaria o arquétipo do qual desacreditar, mas também a se imitar (e, assim fazendo, a se ultrapassar $)^{26}$. Foi apenas mais tarde que aprendeu a formular seu desprezo para com a art informel, que também era embaraçosa: "Eu desprezo artistas que se descarregam em suas pinturas, como ocorre hoje, com frequência. Que mórbido! Em vez de pensar no belo, no bom, no verdadeiro, eles vomitam, ejaculam, cospem toda a sua horrível complexidade, apodrecida e infecciosa, em suas pinturas, como se fosse para se desonerar e atirar o peso nos 'outros', 'os espectadores' do trabalho, com toda a carga

Yve-Alain Bois A relevância de Klein hoje 
que, em Haguenault

peintures, essas

anotações geográficas

são convenientemente

complementadas por

informações sobre a

"proveniência" das

"obras" - informações

claramente fictícias, mas desta vez

oferecidas de acordo com a convenção:

"Haguenault/Páris,

1951 (162 x 97), coleção

Raymond Hains", por exemplo.

25. ROSENTHAL,

op. cit., p. 99. Essas

observações são

baseadas na cópia que

Rosenthal estudou

nos arquivos de Klein

Ireproduzida em

Houston, mas não

em MNAM), assim

como em uma outra

cópia que teria sido

enviada por Klein à

mãe, recém-saída

da pequena prensa

pertencente ao seu

amigo impressor de

Madri (conversa com

o autor, 15 jun. 2006).

As outras cópias

reproduzidas e exibidas

desde a morte de Klein,

em que as dimensões

dadas nas legendas

não correspondem

de modo algum às

dimensões reais dos

retângulos de papel

colado, são, segundo

Rosenthal, incorretas e

póstumas. Ver ibidem,

p. 231 , nota 43 , e, do

mesmo autor, Comic

relief. Artforum, 33, n.

10, p. 93-97; 130; 136,

verão 1995. Este último

artigo, considerando a

exposição organizada

por Stich, critica esse

autor por ter exibido

uma das cópias

incorretas e por se

recusar a acreditar

que a correspondência de sua frustração e amargura ressentida" ${ }^{27}$. Apenas a posteriori, depois de ter escolhido uma identidade como artista (mas, daquele ponto em diante, tudo aconteceria muito rápido, e cada vez mais rápido, até o momento de sua morte prematura) é que Klein seria capaz de entender exatamente o que odiava na cultura para a qual havia sido tragado.

Não obstante o que disse mais tarde, seus primeiros monocromos eram, acima de tudo, gestos parricidas, que de modo algum haviam sido concebidos como trabalhos de arte. Em um de seus muitos relatos autobiográficos (que servem para fortalecer sua legitimidade, tal como Yves peintures), Klein menciona as superfícies monocromáticas que havia pintado em 1946 (aos dezoito anos), ao mesmo tempo em que fazia coisas como "cavalos no campo" e "cenas de praia", ou "composições com forma e cor", sob a influência de seu pai e de sua mãe, respectivamente. Conforme relata, era para "ver, ver com meus próprios olhos, o que era visível no absoluto. Eu não considerava esses esforços como uma possibilidade pictórica na época, até o dia, cerca de um ano depois, em que disse: 'Por que não' [...] Contudo, não mostrei nada ao mundo de imediato. Eu esperei”28. Céticos apontarão aí a edulcoração dos julgamentos retrospectivos - e parece que Klein pré-data em vários anos seu "por que não" metafísico, esse momento "que decide tudo na vida de um homem”, o "sinal para um artista promissor, a indicar que o arquétipo de um estado novo das coisas se havia configurado, amadurecido, podia aparecer no mundo"29 -, mas, entre outros ensaios monocromáticos precoces, este me parece corroboraro mito: em Londres, em 1950, quando trabalhava para um moldureiro (com quem aprendeu, entre outras coisas, a arte do douramento e a técnica de montar de que se serviria mais tarde), ele declarou o seguinte, ao mostrar pequenos monocromos em pastel a seu amigo Claude Pascal: "Encontrei o que quero fazer". Uma eureca tão incerta quanto agressiva já que, depois de pendurar seus pastéis na parede do apartamento que ele dividia com Pascal, convidou o professor de inglês de ambos para rir de sua piada ${ }^{30}$. "Encontrei": encontrei a maneira de obter o melhor de todos eles (seus pais, os amigos deles, críticos e pintores, a alta cultura); a maneira de obliterá-los obliterando suas obras. Quatro anos mais tarde, Yves peintures continuou a servir a essa lógica adolescente, do mesmo modo que o envio, deliberadamente provocativo, ao Salon des Réalités Nonvelles de 1955 (o fórum anual de sua mãe), de Expression de l'univers de la couleur mine orange (o primeiro monocromo de grande formato, ostensivamente colorido à base de água e pigmento, com um rolo). Mais ainda do que o pequeno volume de 1954, foi tal eclosão no cenário público, intencionalmente escandalosa, que estava destinada a mais tarde tornar-se seu verdadeiro "por que não" (a pintura não foi admitida no Salon, como se esperava, e Klein provocou um alvoroço, de modo que seu status de "rejeitado" - como Manet! - entrasse devidamente para os anais da história). 
milímetro/centímetro era um aspecto importante da concepção de Klein, justificando por esse mesmo fato a produção descuidada das

cópias póstumas. $\mathrm{Na}$ cópia recentemente

exibida em Frankfurt e reproduzida no catálogo (BERGGRUEN, Olivier; HOLLEIN, Max; PFEIFFER, Ingrid. Yves

Klein. Ostfildern-Ruit: Hatje Cantz, 2004, p. 12-13), não apenas essa correspondência de dimensões não é observada nas legendas, mas dois dos retângulos estão "assinados" à direita lassinatura impressa em itálico: "English" [Inglês]). Um desses retângulos assinados, alaranjado, parece prenunciar Expansion of the color orange [Expansão da cor laranja], de 1955 lo único monocromo que está assinado, ou melhor, carimbado com uma inscrição, também em itálico: “ $\mathrm{K}$. mai. 55”). Nenhuma das pranchas é assinada na "primeira" cópia reproduzida por Rosenthal, mas esse autor viu vários retângulos de cor nos arquivos de Klein, do mesmo tipo usado no livro, nos quais uma "assinatura" foi impressa. Isso parece indicar que, num dado momento enquanto

fazia esse livro, o artista pensou em distorcer ainda outra marca de autenticidade institucional. Rosenthal nota que, "se Klein tivesse ajustado esses papéis coloridos 'assinados' aos
Os críticos de Klein frequentemente o apresentaram como um ator afetado e patético, um tipo de mau palhaço protofascista, e é verdade que quanto mais ele era acusado de má-fé, mais exagerava seu personagem e sua bizarria. Mas Adorno, em sua discussão sobre Wagner, nos adverte tanto da armadilha que Klein constrói (e com a qual nos testa), como da crítica que seu discurso e cada uma de suas atividades implicaram, de modo paradoxal e astucioso. Porque Klein trazia à tona, com todo o savoir-faire de vanguarda acumulado desde Wagner, uma das condições essenciais da arte moderna, pelo menos desde Courbet e Manet (desde a crise de representação que norteou os trabalhos de ambos). É a consciência de que o risco da fraudulência, o risco de ser motivo de chacota e de se ver denunciado como um rei que está nu tornou-se um risco necessário, mas é, também, a consciência de que cada obra de arte deve confrontar esse riscodeve mesmo solicitá-lo, desafiá-lo - caso se trate de ser totalmente autêntica. Mais do que qualquer outro artista dos anos do imediato pós-guerra, Klein experimentou essa condição como se assombrado por ela (apenas Beuys chega perto; Warhol é muito cool). Daí, por exemplo, suas inúmeras fantasias sobre uma nova ordem econômica mundial, livre deste "medium fixante"31 que é o dinheiro (a economia sendo o domínio do valor por excelência); sua fábula brilhante sobre a série de monocromos azuis de dimensões idênticas, na mostra que realizou em Milão, em 1957 (a anedota que vingou: muitos hoje estão convencidos de que essas pinturas foram todas colocadas à venda por diferentes preços, embora a ideia só tivesse ocorrido a Klein mais tarde); sua obsessão paranoica por direitos autorais e cronologia.

A mitomania de Klein é notória. Suas invencionices são várias as registradas pelos historiadores começaram muito cedo, talvez porque ele tenha sido reprovado no exame de ingresso na universidade, tal como sugere McEvilley: ele disse que Klein frequentou a Academia da Marinha Mercante, que tocava com Claude Luther em clubes de jazz, que criava cavalos na Irlanda etc. A anedota que se segue - uma dentre milhares - tipifica o tom de suas inúmeras histórias.

Para retornar orgulhoso do Japão, onde havia passado um ano e meio para aperfeiçoar sua prática de judô, ele precisou obter o título de "4 Dan de Kokodan" ("sem isso, não poderia retornar, teria perdido tudo”, escreveu à sua supremamente generosa Tia Rose). Mas o nacionalismo japonês foi um obstáculo poderoso (seus examinadores "decidiram não promover com o título um estrangeiro sem que ele tivesse vencido pelo menos dez vezes ou sem que eles fossem adulados com dinheiro"). Embora geralmente não tivesse vergonha de pedir dinheiro a sua tia, ele odiava a ideia de comprar o seu título ("tenho 
tamanhos variados das pranchas na

versão correta, isso

teria resultado no

aparecimento de

tamanhos variados

de assinatura" lop.

cit., 1982, p. 131, nota

46). Certamente, mas

esse expediente teria

assinalado talvez

depressa demais o

caráter fictício das assinaturas

26. Sobre Klein e

Mathieu, ver, em

particular, MCEVILLEY,

op. cit., p. 67;

ROSENTHAL, op. cit.,

1982, p. 94; 124, e

STICH, op. cit., p. 175;

189-90; 223. Klein

escreveu um texto

pequeno mas ambíguo

sobre Mathieu, não

publicado em vida.

em que transparece

certa admiração (In:

DEP, op. cit., p. 343).

Na sua palestra na

Sorbonne, no entanto, embora ele não cite o nome de Mathieu

(e ninguém na época

deixaria de entender),

é ele o alvo (ver KLEIN,

Yves. Conférence à la

Sorbonne. In: DEP, op.

cit., p. 144-145 - toda

a passagem sobre os

imitadores da caligrafia

japonesa e fanáticos

por velocidade em

pintura).

27. Idem, L'aventure monochrome. In: DEP, op. cit., p. 240-241. Há outras versões menos violentas (publicadas antes) dessa passagem.

28. Idem, Le dépassement de la problématique de l'art.

In: DEP, op. cit., p.

80-81.

29. Ibidem. sido muito sincero no judô até agora; não quero qualquer envolvimento de tráfico de dinheiro para comprar minha posição"). No entanto, ele não teve escrúpulos para inventar um novo subterfúgio ("mas há um jeito de impressioná-los, de fazê-los entender que quando eu retornar serei uma figura muito poderosa na França, e será vantajoso para eles terem-me do seu lado, fazendo a mim esse favor especial de me dar o $4^{\circ}$ Dan antes de minha partida"). Ele então solicitou a cumplicidade da sua inocente fada madrinha, convocada a escrever ao chefão do judô no Japão: "Escreva rápido, tantine [tiazinha], mas construa bem a sua carta..." 32 . A carta deve ter sido "bem construída", porque funcionou in extremis - embora para dar em nada, já que a Federação Francesa de Judô se recusaria, no final, a ratificar o título dado pelo Kokodan. Mas importa notar aqui a parcela de verdade (de "sinceridade") que Klein se empenhou em preservar, mesmo mediante a manipulação mais desonesta. Você pode mentir o quanto quiser, contar todo tipo de história, desde que os fatos alegados descrevam a realidade tal como deveria ser (quando a "verdade se torna realidade") ${ }^{33}$ - a venalidade pura e simples, todavia, é um veneno capaz de corromper até o mito.

Com referência à venda de "pinturas imateriais" "durante" a exposição Vazio na galeria Iris Clert, em 1958 (mais uma data antecipada), Klein afirmaria, em 1959: "Acreditem em mim, vocês fazem seu dinheiro valer quando compram pinturas assim. Sou eu que estou sendo enganado ao aceitar dinheiro"34. Ouro puro, o símbolo da inalterabilidade desde tempos imemoriais, ainda mais quando é jogado nas águas do Sena durante uma cerimônia de supremo potlatch (o ritual em que todos os compradores de "zonas imateriais de sensibilidade pictórica" teriam de participar), o ouro é o que apagaria a cicatriz da corrupção monetária (o texto que acabo de citar fala de uma exposição coletiva em Anvers, em março de 1959, na qual o ouro apareceu pela primeira vez na panóplia de Klein: ele estabeleceu o preço para sua obra virtual - existente somente através da presença e do gesto bombástico do artista - em uma barra de ouro de um quilo ${ }^{35}$. Mas, durante sua visita a Nova Iorque, ele quase admitiria que a transfiguração fiduciária do nada puro em outro (que nesse meio tempo ele havia aperfeiçoado com suas "zonas de sensibilidade") era charlatanismo e que sua alquimia eficiente resultava apenas da credulidade de seu público (ou antes, de alguns entusiastas). "Pode parecer incrível, mas realmente vendi vários desses estados imateriais pictóricos" ${ }^{\prime 36}$.

Esse entrelaçamento de verdadeiro e falso em nenhum lugar é mais chocante do que nos textos de Klein sobre sua exposição da "época blu" (a mostra para a qual ele decidiu a posteriori fixar um preço diferente para cada pintura, todas de mesmo tamanho, todas pintadas com o International Klein Blue). A esse respeito, ele explicitamente faz referência ao valor "real" 
30. Cf. MCEVILLEY, op. cit., p. 30; ROSENTHAL, op. cit., 1982, p. 96, e STICH, op. cit., p. 23.

31. 0 autor alude, neste caso metaforicamente, ao fixador químico da cor IKB (International Klein Blue), que o artista patenteou.

A cor resultava da mistura de pigmento puro com uma resina sintética, normalmente aplicada como fixador; tal mistura garantia adesão e estabilidade aos pigmentos sem perda de sua vibração luminosa. [Nota da revisora da tradução].

32. MCEVILLEY, op. cit., p. 36-37. Essa carta foi publicada na íntegra por Stich em várias ocasiões; Klein não hesita em caracterizar a carta que ele pediu para que sua tia escrevesse como um blefe la palavra até aparece em letras maiúsculas). STICH, op. cit., p. 35-36.

33. Os títulos da primeira parte de “L'aventure monochrome", uma coleção de textos em que Klein trabalhou esporadicamente mas que não foi publicada na íntegra até recentemente, eram “Le vrai devient réalité ou pourquoi pas!".

34. KLEIN. Le dépassement de la problématique de l'art, op. cit., p. 94.

35. Idem, Conférence à la Sorbonne, op. cit, p. 121. Ver, a respeito desse ponto, a análise muito boa de RIOUT, da obra (isto é, um valor "invisível" aos olhos, para o qual um preço todavia pode ser estabelecido) e ao problema genérico do falso na arte:

Desse modo, estou à procura do valor real da pintura, isto é, suponhamos duas pinturas rigorosamente idênticas em todos os seus efeitos visíveis e legíveis, como linhas, cores, desenhos, formas, formato, espessura da tinta e técnica em geral, mas uma é pintada por um "pintor" e a outra por um "técnico" habilidoso, um "artesão", embora ambos oficialmente reconhecidos como "pintores" pelo público; esse valor real invisível significa que um desses dois objetos é um "quadro" e o outro não. ${ }^{37}$

Em um dos manuscritos desse texto, Klein acrescentou, no final da passagem, entre parênteses, os nomes de Vermeer e do famoso falsificador Han van Meegeren, que havia sido surpreendentemente bemsucedido em enganar peritos até que fosse levado, de modo espetacular, aos tribunais depois da guerra ${ }^{38}$. Talvez Klein tivesse desistido de aludir a van Meegeren, na versão final de "L'aventure monochrome" ["A aventura monocroma”, porque as imitações produzidas pelo último provaram ser demasiado dessemelhantes de seus modelos (portanto marcando uma diferença visível - embora não percebida pelos historiadores da arte, todos cegos, claro - e não o tipo que ele buscava especificar). Em todo caso, a dança do verdadeiro/falso é essencial para a posição do Klein: é o que lhe permitiu simultaneamente lamentar o desencantamento do mundo e, de modo irônico, haurir substância e subsistência dele (relembrando suas escapadas juvenis com Arman e Martial Raysse, ele declarou ter exclamado na época "que o kitsch, o estado de mau gosto, é uma nova noção em arte: 'a grande beleza não é realmente bela se não contiver mau gosto, um elemento autoconsciente do artificial com um toque de desonestidade" ${ }^{39}$ ). Como Rosenthal analisou soberbamente,

Há, no mínimo, três tons de voz para o mesmo conjunto de palavras sobre o problema de discernir o "valor real" da pintura [na passagem citada acima]: o tom de um crítico que lamenta a situação em que historiadores da arte tenham motivos questionáveis para fazer atribuições e que pintores abstratos possam perpetrar fraudes; o tom de um impostor, que sugere poder estar compactuando com a atividade que critica; e o tom de um verdadeiro artista, que, ao quebrar os tabus dos artistas e permitir a imputação, mesmo a si próprio, de que alguns artistas podem ser hipócritas, mostra quão sincero ele é. ${ }^{40}$

Resumindo, em um mundo em que tudo se tornou mito e espetáculo, somente a espetacularização do mito e do espetáculo podem conter uma parcela de verdade: o ato de demonstrá-los. E aqui voltamos a Adorno e Wagner.

Yve-Alain Bois A relevância de Klein hoje 
op. cit., p. 88-89.

36. KLEIN, Yves.

Chelsea Hotel

manifesto. In: DEP,

op. cit., p. 298,

originalmente escrito

em inglês com a

colaboração de

Neil Levine e John

Archambault. 0 relato

mais preciso das

"zonas imateriais de

sensibilidade pictórica"

e sua análise mais

rigorosa podem ser

encontrados no livro de

RIOUT, op. cit,

p. 96-116.

37. KLEIN. L'aventure monochrome, op. cit., p. 235. Estou citando a tradução de Rosenthal

(In: Houston, op. cit., p. 105).

38. Esses parênteses aparecem apenas como uma nota de rodapé na edição dos escritos. Encontramse na publicação do mesmo texto em

MNAM, op. cit., p. 173.

Sobre o escândalo de van Meegeren, ver

ROSENTHAL, op. cit., 1982, p. 133-34, nota 90

39. “Klein, Raysse, Arman: des Nouveaux Réalistes" [Klein,

Raysse, Arman: os Novos Realistas], debate moderado por

Sacha Sosnowsky,

1960, transcrição publicada em MNAM, op. cit., p. 263.

40. ROSENTHAL, op. cit., 1982, p. 109.

41. Cf. BOURSEILLER, Christophe. Vie et mort de Guy Debord. Paris: Plon, 1999, p. 109-112.

Foi Debord que escolheu uma pequena pintura
Mas o meu desvio por Wagner não foi motivado apenas por esta questão da delegação da arte ao espetáculo. Se fosse esse o caso, um modelo teórico mais direto do que o oferecido por Adorno teria sido Guy Debord, com quem Klein teve (por um tempo) excelente relacionamento - chegou mesmo a oferecer-lhe um monocromo -, até que o chefe da Internacional Situacionista o insultasse em sua revista (por sinal, eles usavam a mesma retórica peremptória - e creio ser um equívoco denegrir as habilidades da escrita de Klein se celebram-se as de Debord) ${ }^{41}$. A busca obsessiva pela verdade, pelo que Klein chamou de "a marca do imediato", concerne ainda a outro legado do pensamento wagneriano, que teve considerável importância na cultura francesa no final do século dezenove - isto é, o simbolismo (os membros desse movimento consideravam Wagner um de seus maiores heróis). Ao se ler os textos de Klein, não há como não ficar abalado pela extrema semelhança deles com aqueles textos escritos, por exemplo, por Georges-Albert Aurier, Gustave Moreau, Charles Morice e até mesmo por Gauguin. Klein, provavelmente, não tinha familiaridade com os escritos desses poetas e pintores ${ }^{42}$, mas o divertido Cosmogonie des RoseCroix [Cosmogonia dos rosacrucianos], de Max Heindel, no qual ele esteve profundamente imerso por longo tempo, deu-lhe acesso (mediante uma completa indigestão, mas as consequências disso são irrelevantes), de modo indireto, ao que era a base comum de ambos, uma ideologia difusa, tangida por neoplatonismo e Schopenhauer ${ }^{43}$. Ao escrever que "a mente não se nutre, não absorve e não dá nada, não rejeita, compreende tudo, vibra com a vida, “é”"44, Klein (sem o saber) parafraseia o Uno de Plotino. Do mesmo modo, quando fala em emanação, em envolver a atmosfera, em radiação invisível, entusiasmo, êxtase, abolição do movimento, vaporização do eu, daquilo que está além do pensamento, de unidade absoluta, é vocabulário neoplatônico copiado com exatidão dos simbolistas. Mesmo seus contumazes fatos consumados (a racionalização a posteriori), que ele não tardou a manejar com desenvoltura, parecem ilustrar a doutrina de Plotino (de acordo com este, na criação artística "nada resulta de consequências lógicas, da reflexão; tudo acontece antes que se possa atinar com consequências, antes que se reflita; porque todas essas operações vêm depois, do mesmo modo que o raciocínio, a demonstração e a prova" ${ }^{35}$ ). A ideia mesma de uma "visão inteligível", tão cara à filosofia neoplatônica, é bastante próxima daquela à qual Klein aspirava (ainda que, provavelmente, tivesse considerado a expressão um oximoro): algo como "a visão sensível da qual alguém teria removido precisamente tudo o que fosse sensível e representativo, isto é, todos os obstáculos, as divisões e traços de opacidade", uma visão a remover "a distância que separa os objetos da visão sensível" e que "simultaneamente abole a distância que separa o sujeito que vê do objeto visto" ${ }^{46}$. 
(para grande surpresa de Klein), "porque eu posso colocar no bolso do meu casaco de baeta". Bourseiller dá bastante informação confirmando a amizade entre Klein e o grupo do futuro Situacionismo

Inotadamente, "em 1956, ele pintou uma peça a quatro mãos com [Asger] Jorn, Ralph Rumney e Wallace Ting"). Em 1952,

Klein compareceu à exibição de Hurlements en faveur de Sade [Uivos para Sade], o primeiro filme de Debord la tela permanece totalmente branca durante os diálogos e totalmente preta durante os longos intervalos de silêncio).

Quando a amizade deles acaba, Debord acusa Klein de plágio.

Mas as surpreendentes afinidades entre Klein e certas produções da Internacional Situacionista vão bem além da anedota, especialmente com relação às utopias urbanas e arquiteturais de Klein, que lembram incrivelmente as de Constant.

42. Ele leu muito pouco: histórias em quadrinhos (Tintin e Mandrake o Mágico); depois Cosmogonie dês Rose-Croix de Heindel, ao qual ele se referiu incansavelmente durante dez anos (entre 1946 e 1956); depois o diário de Delacroix que ele preferia às suas pinturas, e, finalmente, começando em 1958, alguns capítulos de vários livros de Bachelard.

43. Para as páginas que se seguem, sou
Poderíamos sorrir, chamar isso de bugiganga idealista e obsoleta e perguntar como o débito (inconsciente) de Klein para com uma antiga filosofia ressuscitada há mais de um século pelos simbolistas poderia ter o mínimo interesse para a interpretação de sua obra, mas essa pergunta também poderia ser feita com relação aos próprios simbolistas - com exceção, talvez, de Mallarmé, que optou por Hegel (Klein cita o poeta, mas sem estar familiarizado com ele, tendo encontrado citações dele em Bachelard). A pergunta, de fato, não é sobre débito algum, mas sobre como este débito é usado. Como Pierre-Henry Frangne nota, "no neoplatonismo, o simbolismo encontrou os meios filosóficos de, simultaneamente, manter e reduzir a exigência de transcendência e imanência, como também a de dualismo e monismo (do uno e do múltiplo, de sujeito e objeto, de ver e visto, de alma e corpo, ideia e sensação). Tudo isso no interior de uma filosofia que procura desenvolver a 'simplicidade do ver' através de um processo de subtração e desatamento, uma vez que o divino, sendo invisível, não admite predicação ou determinação, mas apenas negações" ${ }^{47}$. Se substituirmos "divino" por "imaterial", chegamos basicamente ao programa de Klein. No lado "transcendência" do livro de contabilidade, encontramos a busca pelo absoluto, a infinitude azul, a "sublimação" (uma das palavras favoritas de Klein, de acordo com Arman) ${ }^{48}$, obsessão pela morte e muitas outras características. No lado da "imanência": a exortação constante à "presença", o desafio de cada meditação, a paixão cega pelo efêmero, a preferência pelo fogo que faz arder a obra e o homem, mais do que pelos restos derrisórios de cinza. Entre os dois, ou antes, dialeticamente, no emaranhado de ambos, temos o conceito de obra de arte como marca material de uma força vital poderosa demais para ser domada, mas também demasiado difusa para ser representada ou intelectualmente apreendida. Em termos de dualismo, temos a organização inteira, extremamente complexa, das exposições de Klein, tão bem descritas por Riout, cada uma concebida como o triunfo do imaterial sobre um contexto material que age por contraste, cada uma encenando algo como uma encarnação antes da ascensão (ou pelo menos da levitação). Em termos de monismo e da "simplicidade do ver", finalmente, temos todas as declarações de Klein contra a composição, as mais lúcidas do seu tempo (depois daquelas feitas por Wladyslaw Strzeminski e pouco antes daquelas feitas por Frank Stella e Donald Judd).

Em suma, embora o pot-pourri sincrético dos textos de Klein não seja muito animador, ele é coerente. Mas essa consistência (que, conforme creio, deve-se ao viés neoplatônico do seu jeito de pensar, inconscientemente, por meio de Heindel) não teria interesse se não lhe tivesse permitido desenvolver, apesar de todos os seus defeitos, uma obra de impacto. Por um lado, esta obra levou ao limite uma proposta que havia atraído pintores pelo menos desde Malevich (a parousia da cor pura). Por outro lado, no cenário 
infinitamente grato ao livro de Pierre-Henry

Fragne: La négation à

l'oeuvre: la philosophie symboliste de l'art (1860-1905). Rennes:

Presses Universitaire de Rennes, 2005.

44. DEP, op. cit., p. 325

45. Apud FRAGNE, op. cit., p. 81-82.

46. Ibidem, p. 83.

47. Ibidem, p. 87.

48. Apud MCEVILLEY, op. cit., p. 51.

49. MANCUSI-UNGARO, Carol. A technical note on IKB. In: Houston, op. cit., p. 258-259. da arte francesa (e europeia), ela representou um despojamento irreversível e sem precedentes. Gostaria de concluir detendo-me um instante nesses dois últimos pontos (cor pura e despojamento).

Sabemos do orgulho e do ciúme com que Klein guardava sua invenção do IKB, o International Klein Blue. Ele até o patenteou. Críticos e historiadores (com exceção de Restany, claro) tendem a usar o termo invenção cautelosamente, entre aspas, sob o pretexto, como Carol Mancusi-Ungaro confirmou há 25 anos, de que a fórmula química do IKB não havia sido desenvolvida pelo próprio Klein, mas por um empregado da Rhône-Poulenc: a resina sintética que permitiu a ele fixar os grânulos de pigmento puro sem que eles perdessem a saturação foi providenciada, a seu pedido, por um vendedor de tintas e ferramentas astuto que se havia interessado por seus experimentos (foi também graças a ele que Klein tropeçou nas esponjas $)^{49}$. Mas é o "a seu pedido" que importa aqui: muitos artistas antes de Klein mostraram-se descontentes diante do fato de que, quanto maior o poder de fixação (lamentavelmente, em proporção inversa à sua fragilidade) de um meio (ou aglutinante), mais turva é a intensidade do pigmento que ele deve fixar (o pastel é uma técnica quase sem meios, quase pigmento puro - é extremamente frágil embora suas cores sejam muito saturadas; na extremidade oposta do espectro há a pintura a óleo, que é robusta mas cujas cores são alteradas pelo óleo aglutinante). Com sua inabilidade infantil para aceitar uma resposta negativa a qualquer dos seus desejos, para aceitar o fato de que obstáculos materiais podem, sim, existir (uma mentalidade utópica compartilhada por todos os inventores), Klein recusou o dilema "saturação-fragilidade/perda de intensidadeestabilidade”. Fascinado diante dos frascos de pigmento puro (em pó) na loja do vendedor de tintas, ele logo perguntou se ainda não se haviam descoberto meios técnicos para fixar, de modo permanente, a vivacidade da cor pura ("a matéria-prima da sensibilidade”). Daí a fórmula do IKB (que, além disso, não demoveu Klein de exibir uma bandeja trazendo pó de pigmento azul, solto, na galeria Collette Allendy, em 1957, como se prestasse homenagem à sua epifania diante dos frascos de pigmentos).

$\mathrm{O}$ resultado da sua tenacidade é memorável: nenhum pintor antes dele havia sido tão bem-sucedido a ponto de obter tal riqueza, tal profundidade de cor sem recorrer ao expediente do contraste; nenhum artista havia encontrado os meios (contudo, bastava apenas perguntar) de manter a saturação máxima de uma única cor com tanta potência e em superfícies cada vez maiores (lembremo-nos dos murais no teatro de 
50. MATISSE, Henri.

Statements to Teriade:

on the purity of the

means. In: FLAM, Jack

(Ed.). Matisse on art.

Berkeley: University of California Press, 1995, p. 122. Seria a expressão de

Matisse "um centímetro quadrado de azul não é tão azul quanto um metro quadrado do mesmo azul" familiar a Klein? (MATISSE, apud ARAGON, Louis. Henri

Matisse: a novel. vol.

2. Trad. Jean Stewart.

Nova lorque: Harcourt

Brace Jovanovich, 1972,

p. 308). Seus murais

oceânicos (wagnerianos) em Gelsenkirchen, em todo caso, provam que o antigo mestre estava certo no que tange a cor e expansão de superfície.

51. SEVERINI, Gino. La peinture d'avant-garde.

Mercure de France, jun. 1917. Reimpresso em SEVERINI.

Témoignages: 50 ans de réflexion. Roma: Éditions Art Moderne, 1963, p. 63.

52. FRANGNE, op. cit., p. 115-118; CLAY, Jean.

Gauguin, Nietzsche, Aurier: notes sur le renversement matériel du Symbolisme.

In: L'éclatement de

l'Impressionnisme. Saint-Germainen-Laye: Musée

Départemental du Prieuré, p. 19-28, 1982.
Gelsenkirchen, alguns medindo 6,09 por 1,82 metros). Ele está longe de ter inventado o monocromo, mas ninguém antes havia conseguido dessa maneira tão encantadoramente simples, com apenas uma única cor saturada - "revolver as profundezas sensuais nos homens"

Bem a propósito, tomo de empréstimo essas palavras proferidas por Matisse, pois de certa maneira Klein realizou o sonho de seu predecessor. Deixemos que a lembrança relatada por Gino Severini guie nosso julgamento:

Um dia, Matisse me mostrou um rascunho que havia feito "do natural" em uma rua de Tânger. No primeiro plano, uma parede pintada em azul. Esse azul influenciava todo o restante, e Matisse deu a ele a maior importância de que fora capaz sem comprometer a construção objetiva da paisagem. Apesar disso, ele teve de reconhecer que não havia capturado uma fração da "intensidade" do azul, isto é, a "intensidade sensorial" que esse azul produzira nele [...]. Ele me disse que, para descarregar essa sensação azul que predominava sobre todas as outras, teria de ter pintado a pintura inteira em azul, como um pintor de parede; mas se tivesse recorrido a essa reação impensada, que teria sido importante apenas no momento da sensação, ele não teria consumado a obra de arte. ${ }^{1}$

Este sonho não poderia se tornar realidade para Matisse, seja por causa das exigências da representação, seja em razão da necessidade de uma transposição (sem o que, conforme ele acreditava, não existiria arte). Mas aí reside o paradoxo: Klein alcançou o sonho de ter apenas cor, sem mediação, em uma intensidade máxima - de tal modo que esta pudesse ser experimentada tão somente no momento, no momento inarticulado da sensação - através de uma lógica mística que parecia estar em completa oposição à afirmação da cor. Porque a cor era, entre todos os elementos não miméticos que compõem as práticas pictóricas, o mais condenado pela estética idealista (em contraposição ao desenho, claro), como algo material e ordinário. Esse paradoxo, essa mudança do idealismo mais extremo para o seu mais estrito oposto não é novidade; é, mesmo, uma das mais fascinantes características do simbolismo - como Frangne demonstrou brilhantemente a respeito de Gauguin e a cor, e como o fez Jean Clay, para além da cor, a respeito de todas as manipulações não miméticas e da importância do material e do corpóreo mesmo para os pintores simbolistas mais enleados pelo inefável (para o católico Maurice Denis, por exemplo) ${ }^{52}$. O paradoxo não é novidade, mas foi exacerbado por Klein com uma ansiedade sem trégua (de modo notável, na textura de suas superfícies monocromáticas, a respeito das quais ele se tornou maníaco). Creio que essa mudança (do ideal para a matéria) governa toda a obra de Klein. Por um lado, quando ele lida somente com

Yve-Alain Bois A relevância de Klein hoje 
53. KLEIN. Le dépassement de la problématique de l'art, op. cit., p. 82

54. ADORNO, T. Gesture. In: In search of Wagner, op. cit., cap. 2, p. 18-32. Em contraste, ver a nota escrita à mão por Klein na partitura de sua Symphonie monoton: "nenhuma eclosão deve ser perceptível - os golpes do arco não devem ser ouvidos". In: DEP, op. cit., p. 346 , nota 3 . a pintura, é ela que conduz a uma de suas invenções mais espetaculares (o próprio formato delgado de alguns de seus primeiros monocromos, na exibição de 1956 na galeria Collette Allendy, por exemplo, medindo 50 centímetros de altura e 2,5 centímetros de largura, uma proporção que não tinha precedentes na história da arte exceto em algumas das pinturas de Barnett Newman, de 1950, que não podiam absolutamente ser familiares a Klein). Por outro lado, assim que começou a explorar novos campos da atividade artística (ele não sentia embaraços quanto à sua habilidade para enfrentar quaisquer empreendimentos), foi essa mudança que o levou quase automaticamente para além de tudo o que os praticantes desse campo jamais haviam entrevisto.

A música talvez seja o caso mais notável: ao despojar, na Symphonie monoton, o som "de uma eclosão [attack] e de uma culminação [ending]", privando assim a música de suas propriedades usuais (do ritmo, até mesmo da melodia - afinal, o que é uma melodia sem começo ou conclusão?), atributos que ainda garantiam a ela uma função narrativa ou figurativa, Klein declarou o som como ele é, em sua própria materialidade, erradicado de suas conexões temporais (o que "cria uma sensação vertiginosa", ele notou, com justeza ${ }^{53}$ ). Foi ainda nesse momento que ele, talvez o primeiro, junto com Cage, rompeu com Wagner, para quem, pelo contrário, a eclosão, o golpe do arco no violino (ou o golpe do sopro), era, de acordo com Adorno, o processo demagógico mediante o qual se fundava a autoridade com que encantava plateias ${ }^{54}$.

O monoton é um equivalente brilhante do monocromo: o único acorde permitido consiste nos ecos harmônicos que o som isolado produz por si próprio, do mesmo modo que qualquer cor vibra apenas porque precipita o eco natural (fisiológico) de seu contraste simultâneo. O que importa é a abolição do contraste formal, da articulação composicional (polifônica, "policrômica", "poliformal") que está sempre relacionada a um conceito cartesiano, do artista como agente subjetivo, e à natureza arbitrária do gosto (do artista e do espectador). Klein foi muito perspicaz a esse respeito, e por isso estava em condições de empreender o processo de despojamento que mencionei há pouco. Permitam-me, primeiramente, destacar como ele tocou no ponto crucial - a posteriori - como de costume. A história é importante e Klein a repetiu várias vezes com algumas variações:

Por que cheguei a esse período azul? Porque antes disso, em 1956, na galeria Collette Allendy e em 1955, [no Clube dos Solitários] na galeria Collette Allendy [sic], eu havia mostrado cerca de 20 superfícies monocromáticas, cada uma de cor diferente, verde, vermelho, amarelo, púrpura, azul, laranja... Meu objetivo era mostrar "cor" e percebi, na abertura, que os espectadores se mantinham prisioneiros de seu modo condicionado de ver: diante 
55. Idem, Conférence à la Sorbonne, op. cit., p. $134-135$

56. Tomo a liberdade de remeter a meu ensaio: Strzeminski and Kobro: in search of motivation. In: Painting as model. Cambridge, Mass.: MIT Press, p. 123-155, 1990.

57. No original: “... were put in the stocks". 0 termo designa uma espécie de cavalete de madeira usado na de todas essas superfícies de cores diferentes apresentadas na parede, continuavam a reconstituir os elementos como decoração policromática. Não podiam imergir na contemplação da cor de uma única pintura de cada vez, e isso era decepcionante para mim, porque, precisamente, eu não admito, de modo categórico, ter até mesmo o jogo de duas cores em uma mesma superfície. Em minha opinião, duas cores contrastantes em uma única tela forçam o observador não a imergir na sensibilidade, no que é dominante, na intenção pictórica, mas, diferentemente, forçam-no a ver o espetáculo da luta entre as duas cores, ou sua perfeita harmonia. Trata-se de uma situação psicológica, sentimental e emocional que perpetua uma espécie de reino da crueldade. ${ }^{55}$

Por certo, tal posição é praticamente idêntica à de Strzeminski, formulada cerca de 30 anos antes (também em textos com os quais Klein não poderia ter tido familiaridade, mesmo que tivesse visto inúmeras pinturas do artista polonês) -, com uma diferença chave, todavia. Os esforços de Strzeminski revelavam um materialismo de base, eram mesmo "realistas" (ele queria abolir toda transcendência, toda referência a um a priori anterior e exterior à existência física, hic et nunc, da pintura $)^{56}$ . Contudo, por um lado, a similaridade surpreendente entre a teoria do Unismo e a de Yves - o monocromo - sugere precisamente o quanto a fenomenologia de Strzeminski estava longe de escapar à metafísica (aprendemos com Derrida que não há nada mais metafísico do que “presença”); por outro lado, no contexto da pintura na França do pósguerra, enfadonho a despeito da estridência existencialista, as exigências maximalistas de Klein tinham um efeito catalisador. (Nesse momento na França, como por toda parte na Europa, era como se ninguém mais lembrasse do trabalho efervescente das vanguardas dos anos 1920 e 1930; pelo contrário, junto aos últimos espasmos do surrealismo, dos vultos monumentais dos grandes totens do início do século - o "estilo tardio" de Matisse, Picasso, Braque, Léger et al. - caracterizavam o trabalho da "jovem escola" uma polidez composicional, o academismo pós-cubista dos artistas abstratos, tanto do gênero geométrico como do figurativo). Em um único lance, o trabalho de Klein tornou inservível toda uma arte pusilânime, a arte de salão que ele detestava em sua mãe - e jovens pintores tinham de escolher sua turma. Alguns poucos pintores abstratos que não se sentiram ultrajados e que compreenderam sua lição foram imediatamente colocados em quarentena ${ }^{57}$ por críticos beletristas (penso em Martin Barré, por exemplo) ${ }^{58}$. Mas esses artistas é que teriam a última palavra.

*Podemos levantar o nariz para o teatro farsesco de Klein, enxergar de outro modo (na direção do sublime) e acreditar que ao agir assim seremos 
Europa medieval como instrumento de castigo.

Era fixado ao redor dos pés, mãos, e, às vezes, da cabeça do condenado, forçando-o a permanecer sentado ou de pé em público.

[Nota da revisora da tradução].

58. A respeito da admiração de Martin Barré pelo trabalho de Klein no final da década de 1950, do efeito imediato que tal interesse teve sobre sua prática pictórica e do modo como foi acusado de traição por críticos que até então o apoiavam, ver minha monografia sobre esse artista: Martin Barré.

Paris: Flammarion, 1993 , p. $5-8$

Ao lado Yves Klein apresenta na Sorbonne a palestra “A evolução da arte para o imaterial”, em junho de1959. capazes de nos furtar de lidar com sua fanfarrice, mas creio que isto seria um grande erro. Pois seus truques eram expedientes populistas - algo repugnantes, sim, mas talvez ele não tivesse muitos outros à disposição com os quais era capaz de lutar contra o espetáculo igualmente pomposo mas ainda mais vazio da alta cultura burguesa de seu tempo (mais vazio porque havia sido aplanado pela indústria cultural embora fingisse ignorar esse fato). Quem quer que se recuse a ver uma denúncia radical da art informel nas fotos que o exibem executando suas "pinturas a fogo" com um maçarico no Centre d'Essais de Gaz de France perdeu o trem. Entretanto, esse ato é virulento, em grande medida, porque é falso: o bombeiro que Klein pusera de pé a seu lado, supostamente para intervir em caso de incêndio, não era realmente um bombeiro, mas um amigo motivado a desempenhar o papel. Nisto reside a relevância de Klein hoje: ele nos mostra como desmoralizar o espetáculo da indústria cultural encenando um ardil ainda maior que o dela. 


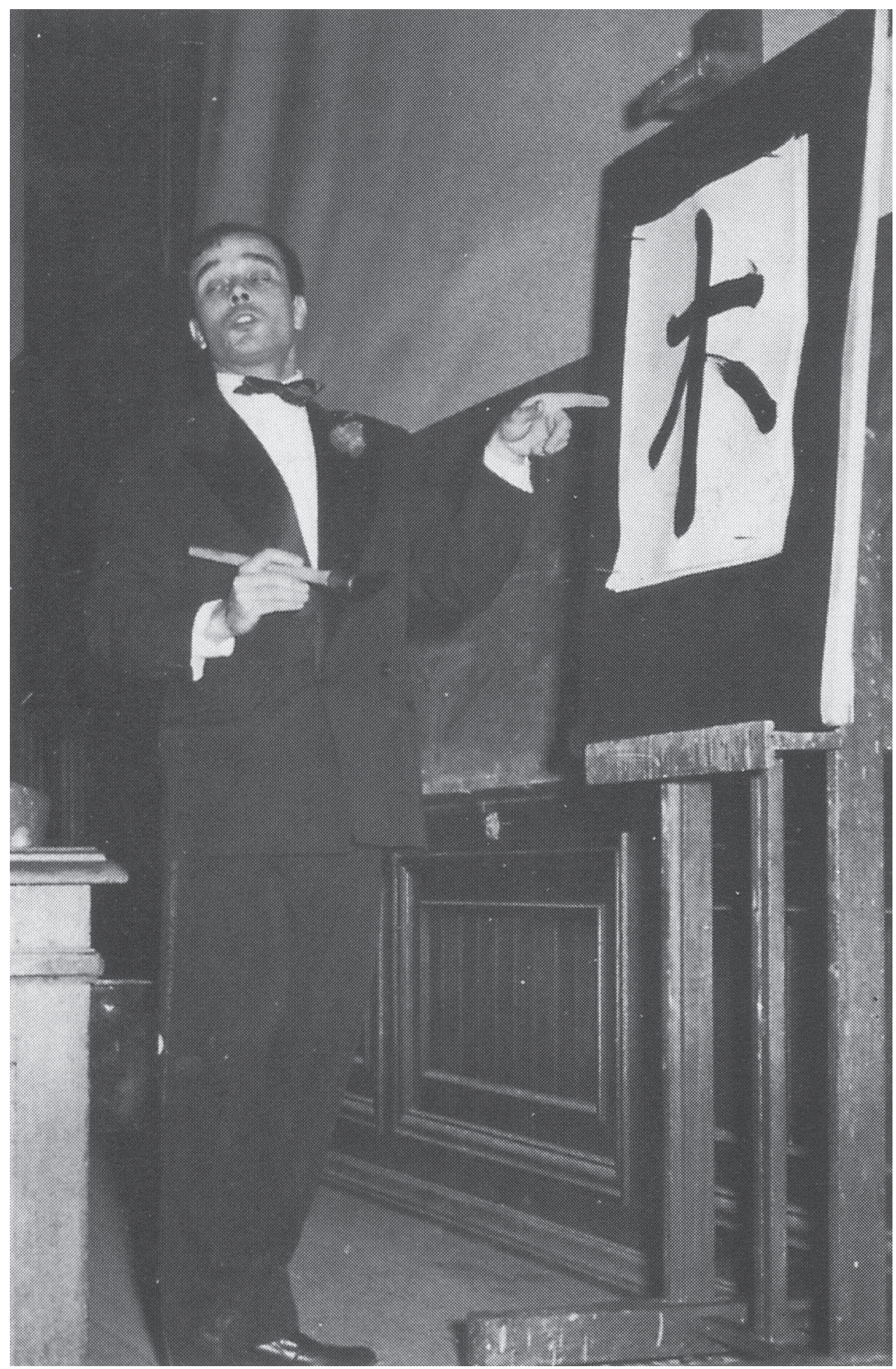

